\title{
Crystal structure of distrontium lanthanum gallium pentaoxide, $\mathrm{Sr}_{2} \mathrm{LaGaO}_{5}$
}

\author{
Th. M. Gesing ${ }^{*, I}$, R. Uecker ${ }^{\text {II }}$ and J.-Ch. Buhl ${ }^{\mathrm{I}}$ \\ I Universität Hannover, Institut für Mineralogie, Welfengarten 1, D-30167 Hannover, Germany \\ Il Institut für Kristallzüchtung, Rudower Chaussee 6, D-12489 Berlin, Germany
}

Received November 23, 1999, CSD-No. 409463

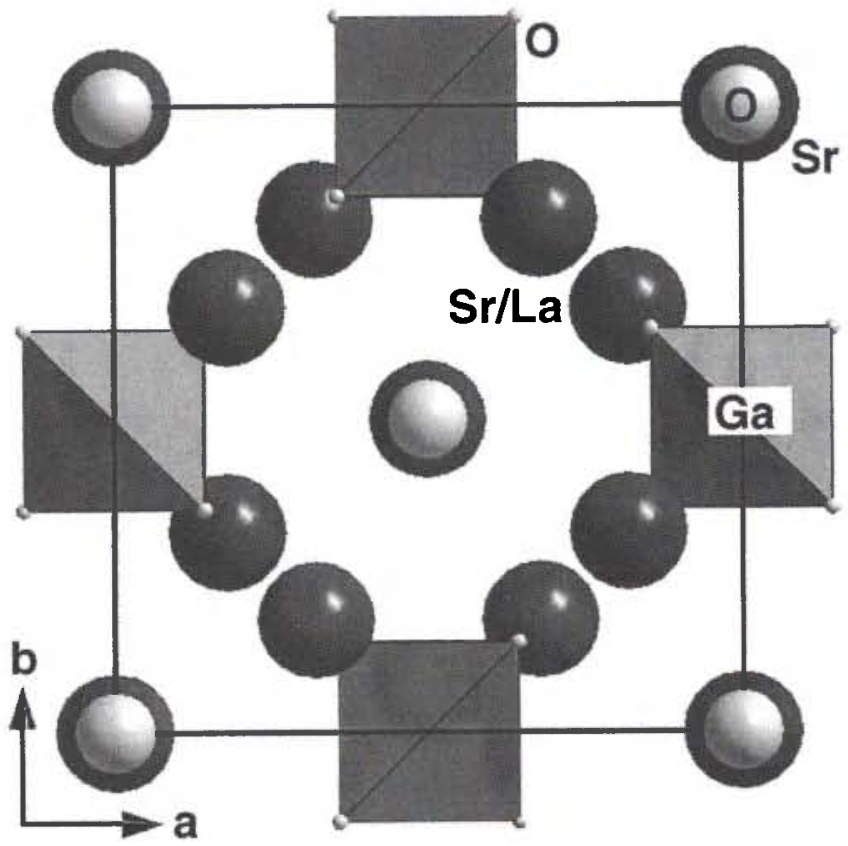

Discussion

Preliminary, lattice parameter of this compound were given by Mansmann [2]. The structure of $\mathrm{Sr}_{2} \mathrm{LaGaO}_{5}$ is isotypic with $\mathrm{Sr}_{2} \mathrm{GdGaO}_{5}$ [3] from which the starting atomic coordinates for the refinement were taken.

Table 1. Data collection and handling.

\section{Source of material}

$\mathrm{Sr}_{2} \mathrm{LaGaO}_{5}$ melts incongruently, therefore it was synthesised by solid state reaction of the single oxides and carbonates, respectively. They were of $4 \mathrm{~N}$ and $5 \mathrm{~N}$ quality and the mixture of them was prepared containing $\mathrm{SrO}, \mathrm{La}_{2} \mathrm{O}_{3}$ and $\mathrm{Ga}_{2} \mathrm{O}_{3}$ in a molar ratio of $4: 1: 1$. The sample was sintered in air in a closed $\mathrm{Pt}$ crucible up to $1573 \mathrm{~K}$ for $20 \mathrm{~h}$. This reaction led to a homogeneous grey product [1]. Because of the incongruent melting of $\mathrm{SrLaGaO}_{4}$ - one of the most favoured candidates for substrates for high-Tc superconductors - primary crystallisation of $\mathrm{Sr}_{2} \mathrm{LaGaO}_{5}$ takes place when starting the crystal growth from the stoichiometric melt composition $\mathrm{SrLaGaO}_{4}$.
Powder: Wavelength:

$\mu$ :

Diffractometer:

Scan mode

$20_{\max }$, stepwidth:

$N(\text { points })_{\text {measured: }}$

$N(h k l)_{\text {measured: }}$

$N(\text { param })_{\text {refined: }}$

Program:

Table 2. Atomic coordinates and displacement parameters (in $\AA^{2}$ ).

\begin{tabular}{lllllll}
\hline Atom & Site & Occ. & $x$ & $y$ & $z$ & $U_{\text {iso }}$ \\
\hline $\mathrm{Sr}(1)$ & $8 h$ & 0.5 & $0.181(1)$ & $x+1 / 2$ & 0 & 0.017 \\
$\mathrm{La}(1)$ & $8 h$ & 0.5 & 0.181 & $x+1 / 2$ & 0 & 0.017 \\
$\mathrm{Sr}(2)$ & $4 a$ & & 0 & 0 & $1 / 4$ & 0.015 \\
$\mathrm{Ga}(1)$ & $4 b$ & & 0 & $1 / 2$ & $1 / 4$ & 0.018 \\
$\mathrm{O}(1)$ & $4 c$ & & 0 & 0 & 0 & 0.032 \\
$\mathrm{O}(2)$ & $16 l$ & & $0.143(8)$ & $x+1 / 2$ & $0.642(5)$ & 0.035 \\
& & & & & & \\
\hline
\end{tabular}

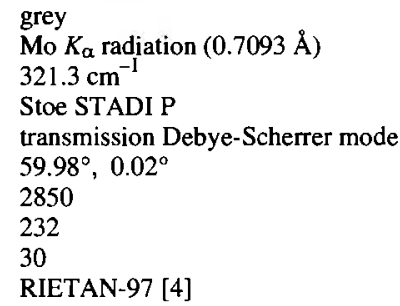

RIETAN-97 [4]

\section{References}

1. Uecker, R.; Reiche, P.; Ganschow, S.; Uecker, D.-C.; Schultze, D.: Investigation of crystal growth of $\mathrm{SrPrGaO}_{4}$ and $\mathrm{SrLaGaO}_{4}$. Acta Phys. Pol. A92 (1997) 23.

2. Mansmann, M.: Crystal structure of tribariumpentaoxymetallates (IV) and isostrctural compounds. Z. Anorg. Allg. Chem. 339 (1965) 52.

3. Nguyen Trut Dinh, Fava, J.; Le Flam, G.: Etude structural et optique de la phase $\mathrm{S}_{2} \bar{G} d \mathrm{GaO}_{5}$ dopee a l'europium trivalent. Z. Anorg. Allg. Chem. 433 (1977) 275-283.

4. Izumi, F.: "The Rietveld Method", ed. by R. A. Young, Oxford University Press, Oxford 1993. 